\title{
Motivating Students to Develop Satellites in Problem and Project-Based Learning (PBL) Environment
}

\author{
http://dx.doi.org/10.3991/ijep.v3i3.2529
}

\author{
J. A. Larsen, J. F. D. Nielsen and C. Zhou \\ Aalborg University, Denmark
}

\begin{abstract}
During the last decade, engineering students in a Problem and Project-Based Learning (PBL) environment at Aalborg University, Denmark, have developed a total of three student satellites. In order to complete such complex projects, it is emphasized that a high level of motivation is needed for the students. Thus efforts have been taken in the context of project management style with this aim. However, it is necessary to discuss this issue from the students' perspective to achieve a better PBL environment, which leads to the research question concerning how the students perceive their motivation in developing satellite projects in a PBL environment. Empirically, a total of 12 student participants have been interviewed. The results show that in project management their motivation is highly stimulated by a series of factors, such as the task characteristics, support of peers, help of supervisors and openness. Nevertheless, the time schedule can be a barrier to motivation.
\end{abstract}

Index Terms-Problem and Project-Based Learning (PBL), Student Satellites, Group Work, Cubesat

\section{INTRODUCTION}

In recent years, PBL has been employed by a growing number of educational institutions to foster qualified engineers. Aalborg University (AAU) in Denmark has a tradition of the PBL approach since 1974. In each semester at AAU, the students are required to complete approximately $50 \%$ coursework and $50 \%$ project work in groups, where they collaborate on solving real-life projects and writing reports. As the objective is to align the education as much as possible with their future professional practice, students, by working on a certain problems, will be able to reflect upon conceptual and methodological frameworks [1].

The literature demonstrates that AAU has been discussed broadly as an influential PBL model in engineering education, especially with regard to the project characteristics of solving real-life problems and interdisciplinarity [2]. The student satellite project is one of the examples in this context. During the last decade, a total of three satellites have been developed, launched and operated exclusively by engineering students at AAU. This huge project was a joint venture between several departments, which included the Department of Electronic Systems, the Department of Mechanical Engineering, the Department of Computer Science and the Department of Energy Technology.

During the satellite construction process, experience and new knowledge regarding management and learning is obtained by the students. However, in order to solve such a long-term, interdisciplinary and real-life project, a high level of motivation is needed from the students. Therefore, an open learning atmosphere is created. The students are encouraged to involve themselves in project management and are allowed to fail some times, although, of course, this strategy would never be practiced in a professional setting, i.e. a company or a space organization. However, in a PBL framework, the primary objective behind all the student satellites from AAU is to develop world-class engineers. Hence, one of the most valuable lessons, which can encourage students to a deeper engagement and to learn much more, is to experience failed designs and decisions. In addition, it is important to stress that the management guidelines are valid for any larger educational hardware or software project, which spans several studies involving several departments and different semesters. Currently, the methods are also being tried out on a student racecar project and an autonomous submarine project at AAU.

In this paper, the PBL theories and the PBL model at AAU are firstly introduced. Then, the means of encouraging students by a series of management methods, which have been used over the years, are explained. The main focus is how to motivate students and how they perceive this motivation in a PBL environment. Thus, by interviewing 12 student participants in the AAUSAT3 satellite project during 2008-2009, the results are expected to contribute to related future studies on teaching engineers using the PBL approach.

\section{PBL IN ENGINEERING EDUCATION}

Recently, PBL has been suggested as a promising strategy to develop the new generation of engineers in more educational institutes. Many studies have explored its effectiveness in fostering qualified engineers [3]. In order to show the evidence supporting the psychological mechanisms explaining how PBL works, de Graaff and Kolmos [4] summarized the main learning principles according to three approaches:

- The learning approach. Problem and project based learning means that learning is organized around problems. It is a central principle for the development of motivation. A problem constitutes the starting point for the learning processes and places learning in context, based on the learner's experience.

- The contents approach concerns especially interdisciplinary learning, which may span traditional subject-related boundaries and methods. It is exemplary 
practice in the sense that learning outcome is exemplary of the overall objects.

- The social approach is team-based learning. The team learning aspects underpin the learning process as a social act where learning takes place through dialogue and communication. However, the students are not only learning from each other, they also share knowledge and organize the process of collaborative learning. The social approach also covers the concept of participant-directed learning, which indicates who has ownership of the learning process and, in particular, the formulation of the problem.

Accordingly, learning in a PBL environment centres on complex, real-world problems that do not have a single correct answer. Students work in collaborative groups to identify what they need to learn in order to solve a problem. The teacher acts to facilitate rather than to provide knowledge directly. This strategy yields a higher level of reflection and understanding compared to "normal" education [5] and, at the same time, the students benefit by learning to work like engineers. As pointed out by de Graaff and Kolmos [4], PBL has become increasingly accepted due to its principles of integrating knowledge across disciplines and developing expected professional competencies among students by bridging university and society.

In practice, this strategy is implemented in a variety of ways in engineering education throughout the world: Project-Based Learning in Spain, Japan and Germany; Project-Led Education in Portugal; Problem-Based Learning in England and the USA; and Problem and Project Based Learning in Denmark [6] [7].

It should be mentioned, that, within the engineering studies at Aalborg University, the way that PBL is used, it is naturally incorporating the CDIO initiative, and the reader is referred to Brodeur et al. [8], Norman, [9] and the references therein for studies in similarities and differences between the two teaching philosophies.

\section{Developing Student Satellite Projects at AALBORG UNIVERSITY, DENMARK}

\section{A. The PBL Model at Aalborg University, Denmark}

Aalborg University (AAU) in Denmark has a tradition of PBL since 1974. Students at AAU are required to complete in each semester approximately 50\% coursework and $50 \%$ project work in groups. The $50 \%$ project work is used within a project group trying to come up with a solution to a given problem, while the $50 \%$ coursework is spent on traditional engineering lectures. Each semester project groups are formed with 3-6 members, which the students themselves organize. The project that the group will work with is either one, which they have found by themselves; otherwise supervisors normally come up with a set of problems, often proposed by the local industry, which the students can choose from. Following this each group is assigned a group room and a supervisor for the semester. The courses and project work load is organized around an estimated workload of 35-40 hours a week, in which period they are expected to be at campus. One of the main ideas behind this group structure is that students are encouraged to help and support one another within the groups, both during problem solving after lectures and within the project work.

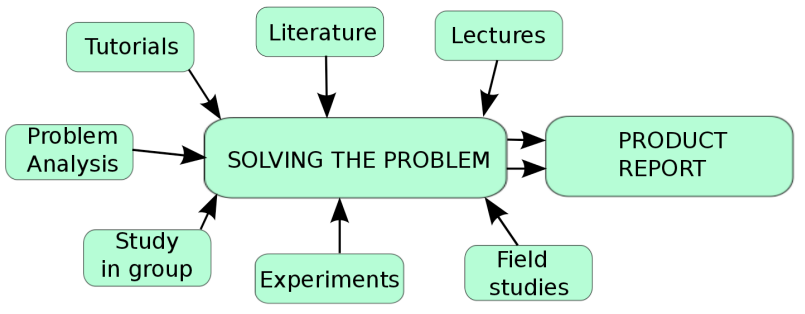

Figure 1. A schematic view of the project activities

Although the students have quite free hands in selecting which project they would like to work with within the project period, then there is an underlying curriculum, which needs to be fulfilled in order to pass the semester, hence it is the task of the supervisor to ensure a sufficient technical level of the applied methods in order to pass the semester.

A typical semester project contains all aspects of a typical industrial R\&D project, similar to the CDIO initiative, from problem analysis and formulation through method selection and prototype development. As documentation for the work, the project group normally writes a 100-250 pages project report describing the development process and the proposed solution. In addition to this, engineering students often develop and deliver a prototype of part of the proposed solution for evaluation as well. The structure of this learning process is depicted in figure 1 .

The students studying at AAU using the PBL model are examined in a comparable curriculum to other master studies in Denmark, and the achieved technical levels are comparable. However, technical engineering students following the PBL structure tends to finish faster, $88 \%$, than at other technical universities in Denmark, 68\% (calculated based on education normed time plus 1 year "Universities Denmark", 2012), which is believed, is due to the social aspect of working together in groups solving the problems, and the relevance of the problems addressed through the projects.

Furthermore, due to the group organization, students are able to cover larger projects, which the local industry appreciates, and as a consequence, most master thesis projects are performed in cooperation with the local industry.

\section{B. Challenges of Student Satellite Projects}

The first student satellite was developed at Aalborg University around 10 years ago. Within AAU, the satellite programme is a joint venture between several departments, which includes the Department of Electronic Systems, the Department of Mechanical Engineering, the Department of Computer Science and the Department of Energy Technology. This programme has been sponsored by government and industry, such as The Danish Maritime Safety Administration. However, the satellite projects have met more challenges than other normal student projects at AAU, of which some are listed below:

The duration of the project is several semesters.

- Cooperation across groups on several different semesters and specializations, e.g. electronics, computer science, mechanics, communication, is necessary.

- The outcome of the projects should be a fully functional satellite, not just a laboratory prototype.

- Rigorous testing and documentation is required.

- Putting the satellite in right orbit is expected. 
- $1 \mathrm{~kg}$ of satellite costs US $\$ 60,000$ to launch into a low earth orbit $(700 \mathrm{~km})$.

Therefore, a single group of students would not able to finish building an entire satellite, or even a subsystem of the satellite, within one semester. From the onset of the project, it is important to think through how the project can be divided into smaller tangible tasks, which efficiently can be distributed across different institutes and semesters. From the staff supervisor's point of view, such large student projects often require additional supervision time, both for managing the project and for applying for funding for covering development and launch costs.

\section{Stimulating Students' Motivation By PBL in DeVEloping SATEllite ProjeCtS}

During the satellite development, two key points that have to be paid more attention in order to get such a complex project moving is motivation of the students and applying a suitable management style. Firstly, a high level of motivation is needed from the students, which ensures that they engage thoroughly in the learning activities. Secondly, a suitable project management style is necessary to build a satellite, with the assistance of supervisors, while at the same time facilitating students' motivation and the collaboration within and between groups. Therefore, a series of project management methods aiming to stimulate motivation are explained below.

\section{A. Invisible Management and Guidance from Supervisors}

For the supervisors, the frames for conducting a single semester project is well known and usually clearly described within the study provisions. A semester group can conduct a traditional semester projects utilizing normal guidance and supervision aid. In the PBL model at AAU, the supervisor meets with the students once a week or every two weeks. The university staff members conduct "invisible management and guidance", which is the basic philosophy of the supervision work. The purpose is not being a project manager in the project, but rather to guide the students in the right direction and occasionally more traditional management in case the project encounters serious difficulties.

It is important to stress, that this strategy is not put in place to reduce the teaching load of the supervisors, but to allow the students to experience how it is to manage a project themselves and letting them mature with the learning process, which also leads to responsibility and ownership of their project. It is a very valuable and meaningful experience for the students. Therefore, in the satellite projects, management is mainly conducted using this philosophy.

\section{B. Putting the Students in Charge}

As mentioned previously, an important method of motivation is increasing the students' ownership of the project. However, a satellite project takes several years and it is hard to have a stable group of students working on it for several semesters. So, in order to ensure continuity, an effective management group is necessary, that can:

- Plan activities in accordance with the educational thematic structuring.
- Structure and control the development in subsystems and break down problems/duties into tangible tasks.

- Be responsible for following up and evaluating the above items.

At first glance this may seem effective - if the employed staff can take care of running the project, then the students can focus on doing the "real work". However, the following questions are important for the role definition in the project:

1. Is the satellite "owned" by university (staff)?

2. Is the satellite "owned" by the students?

3. Is the satellite "owned" by an external partner?

4. Who has copyright to the work?

5. Who is doing all the hard work?

Questions two, four and five naturally lead to the answer that the actively involved students own the satellite project. Construction of a satellite takes far longer than the normal educational curriculum and the students must ensure additional learning like space soldering, space environment testing, high quality PCB design. In general, this is much more than a normal curriculum would require. Thus, by emphasizing the students' ownership of the project, they become more motivated to assume ownership, including management, which involves duties like work schedule, review, handling of analysis and design, allocation of human resources, control of documentation and control of external contacts. In general, the students take on all management with staff management participating in an "invisible" way.

However, a few areas remain in control of staff management:

- Funding and finances - the project does rely on external funding and negotiation with launch providers.

- Negotiation with study boards for integration with the normal educational schedule.

- Difficult decision-making.

- Supervision of the students - a natural part of the educational system.

\section{Building Basic Rules for the Students}

The construction of a satellite takes from 2 to 4 years, which means that the team consists of new as well as older students. For example, in autumn 2010, the AAUSAT3 team had students in the last year of their bachelor's degree and groups both at the beginning and end of their master's studies as well as a few former students that graduated during the summer of that year. It is necessary to establish the rules for the students in order to facilitate collaboration between them. A number of unwritten rules that all students have to follow to some extent:

Rule number one: All students are equal, so the older students are not automatically in control of management. This may appear odd because older students have more skills, but not all sub-projects demand the same level of qualification. For example, in AAUSAT3, the analysis and testing of an on-board operating system was carried out in the 4th and 5th semesters on the bachelor level, whereas the design of an attitude control system was completed in the 3rd semester on the master level. Therefore, the students in higher semesters can recognize and accept 
students in lower semesters. It is natural to show respect for other people to achieve solutions.

Rule number two: Each group appoints a system engineer who represents the group at management meetings. Furthermore, shared responsibility does not exist in the sense that there needs to be one person taking responsibility. This solves two problems: firstly, shared responsibility and, secondly, keeping down the size of the management group. It is not effective to have management meetings with 20-30 attendees.

Rule number three: Everybody has the right to ask for help and nobody can refuse this without a very valid argument. A person's or group's small problem can very quickly become a big problem for the entire satellite if it is not solved sensibly. This is not a problem in our project as people respect rule number one.

Rule number four: Do not cover up mistakes. Covering mistakes is a major risk to the whole project. Moreover, mistakes can be the starting point for developing the right solutions. Openness and honesty is of the highest priority.

The fact that extra effort is needed to develop and produce a whole satellite should not be ignored. Education normally ends where real life starts, meaning that it is normally a prototype or an alpha version which is developed during a semester project, and no credit is given for creating production ready PCB drawings, space soldered PCBs, production tested SW solutions, etc.

\section{Placing Students in "Small" Projects}

As mentioned, the student satellite project has been developed as part of a master engineering programme at AAU. The semesters are all thematic, thus in order to allow educational and satellite developments to meet, the satellite has been divided into a number of subsystems which fulfil these objectives. A few examples are given in table I. The "small" project has to create a prototype for their respective subsystem within one semester.

TABLE I.

EXAMPLE OF SEMESTER THEMES, ALL WITHIN THE DEPARTMENT OF ELECTRONIC SYSTEMS

\begin{tabular}{|l|l|l|}
\hline \multicolumn{1}{|c|}{ Semester } & \multicolumn{1}{|c|}{ Theme } & \multicolumn{1}{c|}{$\begin{array}{c}\text { Small Project in } \\
\text { AAUSAT3 }\end{array}$} \\
\hline $\begin{array}{l}\text { Bachelor } \\
4^{\text {th }}\end{array}$ & Basic digital systems & Selection of $\mu \mathrm{P}$ \\
\hline $\begin{array}{l}\text { Bachelor } \\
5^{\text {th }}\end{array}$ & Embedded systems & Electric Power System \\
\hline${\text { Master } 3^{\text {rd }}}^{\text {th }}$ & Advanced hybrid control & Attitude Control System \\
\hline${\text { Master } 4^{\text {th }}}^{\text {Advanced communica- }}$ & Communication Protocol \\
\hline
\end{tabular}

\section{E. Bringing Prototypes Together}

After having developed prototypes for all the different subsystems the integration starts. For most students this part is at the periphery of the educational curriculum, an intense phase of the project when errors and misunderstandings during the design phase suddenly show up. It is important to maintain a high level of documentation for the individual subsystems, as well as comprehensive test reports showing that everything has been tested according to the specifications. This is very valuable when the integration phase begins and if elements do not work as expected.
For example, the integration and final testing on AAUSAT-II was carried out successfully in the summer holiday on a strict voluntary basis. The students did not attend any lectures or semester projects, so they could focus fully on the goal and work closely together in the Satlab. No formal cooperation model was used, however, for the AAUSAT3 satellite project, a reduced version of scrum [10] was introduced during the summer periods to facilitate the cooperation amongst the different subsystems and catch problems at an early stage. The most important part was the morning meetings, so everybody knew what was going on.

To summarise, in order to motivate students in PBL, supervisors should encourage "learning through practice" in an open group setting. The students feel more comfortable in such a friendly environment, which drives members to suggest novel ideas openly, criticise others' ideas, challenge the status quo, ask naive questions, or admit mistakes because they lack the fear of ridicule or more subtle forms of interpersonal rejection [11]. This type of environment provides an opportunity for skill development and helps maintain the intense and sustained motivation or perseverance found in creative individuals. It also produces students who are self-confident in their social roles within a group, are willing to take risk in the public arena of a classroom, and collaborate with others to interpret and develop solutions from challenging problems [12].

\section{STUdents' PERCEPTIONS ON MOTIVATION IN SATELLITE PROJECTS IN PBL ENVIRONMENT}

As previously discussed, in order to motivate students, a series of management methods have been created along with the development of satellites. However, it is necessary to discuss this issue from the students' perspective, with the aim of evaluating the management efforts. As regards the perceptions of the students, indications for a better future facilitation work can be obtained. This leads to an empirical study about the students' perceptions on their motivation in developing the satellite projects in a PBL environment.

\section{A. Research Method and Data Collection}

In this study, qualitative interviews have been employed, since this method has been suggested as a useful way to examine phenomena in a natural context and to reveal diverse perspectives [13]. The empirical work was carried out with 12 students who participated in the satellite project during 2008-2009. There are seven interviewees from the 6th semester of the bachelor program, 3 interviewees from the 1 st semester of the Master program and 2 interviewees from the 3rd semester of the Master program.

In terms of how students perceived their motivation in developing the student satellite project in a PBL environment, and the concerns of management style, the following topics were covered in the interviews:

- Reasons for participating in satellite project work.

- Influencing factors (both stimuli and barrier) of project management on the motivation.

- Roles of supervisor on the motivation.

The interviews were organized as open-ended questions that allowed for in-depth follow-up. Each interview was 
about 30 minutes. The data was analysed and coded according to key themes, and the results were generated from conversation analysis based on interview transcription.

\section{B. Results}

From the data analysis, diverse points from different interviewees on each interview topic were obtained and summarized according to the topics. Firstly, the four main reasons for participating in the satellite project work for the students were determined. This was followed by a grouping of a series of factors related to project management, such as formal and informal discussion, collaboration amongst different groups and group diversity, which help with motivation. However, time schedule is the barrier and the supervisors have played an "inspirational" role in project work (Table 2).

Moreover, in relation to influencing factors on motivation in Table 2, the students point out that "time schedule" is a barrier to this to some extent. They also suggest the supervisor should give more "direct" input than "invisible" guidance. In addition, the empirical data indicate the multiple ways and influencing factors that interact with each other can be viewed as a whole when they influence motivation, as discussed in the following.

\section{Discussion}

\section{1) Reasons for Participating in a Satellite Project}

As shown in Table 2, there are four main reasons for participating in a satellite project. However, "being interested in making a real-life satellite" is regarded as the most basic reason by students. Though it is a long-term task, each student felt excited that he had an opportunity to participate in parts of the project. This means that the task characteristics of a satellite project motivate students intrinsically.

The students also remarked that they benefitted more from satellite projects than the normal semester projects. However, there are differences between younger and older students when they express this point: 1) students at the end of their bachelor studies and on the first year of their master studies focused on gaining knowledge, since they were required to study fields such as electronics, mechanics, space, physics, oceans and energy, whereas 2) students of 9th semester focused on preparing for future work, because they would graduate sooner and had more employment pressures.

In addition, interviews revealed that some students knew each other before they participated in the satellite projects, and they had experience of working together in the previous semesters. Thus, when one became interested in the satellite project, the others whom he knew were introduced to the groups.

2) Influences of Project Management on Motivation

As shown in Table II, there are multiple factors related to project management on students' motivation. As we expected, the students were involved in the management of learning from the stage of group building, and the project proposals were announced on the website at the beginning of every semester. Those who were interested in this project gathered to discuss the possibility of establishing a group, which can be described as a "peer-arranged" process. The students initiated meetings and decided how to participate. Therefore, the satellite project is conducive
TABLE II.

DATA OF STUDENTS' PERCEPTIONS ON MOTIVATION IN A SATELLITE PROJECT

\begin{tabular}{|c|c|}
\hline Interview Topics & Data Results \\
\hline $\begin{array}{l}\text { Reasons of partici- } \\
\text { pation }\end{array}$ & $\begin{array}{l}\text { - Being interested in making a real-life } \\
\text { satellite } \\
\text { - Expecting to gain more knowledge } \\
\text { through involvement in a satellite project } \\
\text { - Preparation for future employment in a } \\
\text { workplace } \\
\text { - Being introduced to peers }\end{array}$ \\
\hline $\begin{array}{l}\text { Influences of pro- } \\
\text { ject management on } \\
\text { motivation }\end{array}$ & $\begin{array}{l}\text { - Formal and informal discussion in group } \\
\text { - Coetings } \\
\text { ent semesters } \\
\text { - Peer-arranged process of group building } \\
\text { - Group diversity in terms of backgrounds } \\
\text { and skills of members } \\
\text { - Making group rules and initiating group } \\
\text { and supervisor meetings by the students } \\
\text { themselves } \\
\text { - Creating milestones and assigning tasks } \\
\text { - through group meetings } \\
\text { - Sharing leadership } \\
\text { - Eqmmon group goals } \\
\text { - Good relationships between members } \\
\text { - Clarity of members' tasks } \\
\text { - Time schedule }\end{array}$ \\
\hline Roles of supervisor & $\begin{array}{l}\text { - Good communication with student groups } \\
\text { in both meetings and on a daily basis } \\
\text { - Encouraging collaboration and sharing } \\
\text { experience with different groups } \\
\text { - Facilitating deeper learning to help pro- } \\
\text { gress project work } \\
\text { - Dealing with group disagreements } \\
\text { - Generating new ideas in supervisor meet- } \\
\text { ings }\end{array}$ \\
\hline
\end{tabular}

to building a community, where a group of people work together with a common set of goals or interests. And the learning community provides the support network necessary for learning to occur [12].

Moreover, the principle of task-related group diversity was followed in the group building process. As Nijstad, Rietzschel and Stroebe [14] suggest, task-related diversity enhances group performance. The right level of diversity seems to be essential to avoid cognitive uniformity and conformity: group members who have different approaches to the same problem are less likely to get stuck in a rut. Also, the group members should perform the tasks they are good at. Additionally, the members' tasks were not assigned by supervisors, but instead agreed upon through group discussion. If there were some difficulties in learning, members would have more informal discussions about solutions. So the milestones were kept flexible for modification along the way. In practice, students drew timetables as reminders on the blackboards. This, they believed, clarified members' tasks, facilitated effective communication and avoided the overlapping of efforts.

In the interviews the students also noted that they made group rules by themselves; for example, how many hours they should work together every day. Accordingly, a group coordinator, often referred to as the group system engineer, was selected in each student group for cooperating between members and with the other groups. The other members also made different contributions to the group 
management, such as contacting supervisors and sponsors. As a result, everyone was responsible for the progress and success of the tasks. Thus, shared leadership was further realized. As suggested by Wenger [15], "a community needs multiple forms of leadership: thought leaders, networks, people who document the practice, pioneers, etc." The shared leadership creates a division of labor in which each participant is protected from carrying the whole burden.

Furthermore, project meetings were organized once a week in order to support such a complex project, as well as all students and supervisors involved. The meetings also encouraged collaboration between student groups in different semesters. The students worked in one big group and, at same time, they belonged to several sub-groups. From the interviews it was established that the formal and informal discussions were usually the source of motivation, since disagreements often led to deeper debate. In this regard, interviews revealed that students believed that they could benefit from learning in groups. They suggested that the common group goals, support of peers and equal amount of individual tasks, the good relationship of members and the group openness were important to motivation.

\section{3) Roles of Supervisors on Motivation}

As the students mentioned, asking help from the supervisor is a way of progressing new ideas in the project. Usually, the students initiate meeting with the supervisor once a week or every second week. In both formal meetings and on a daily basis, the supervisors stimulated group dynamics by encouraging the sharing of knowledge. According to the students' assessment, supervisors had an "inspirational" role in the groups.

However, when the students were asked to give more suggestions to supervisors, they replied that certain knowledge should be taught directly to some extent, and they want more effective and even "visible" supervision when they meet challenges. On the other hand, supervisors try to stimulate an open group atmosphere and encourage student to interact with each other, thus facilitating the teaching process in an invisible way. For large projects, one of the key management tools is the time schedule for the project. However, the time schedule is viewed as two sides of the same coin by the students - it stimulates learning, but can also be a barrier to motivation, when trying to follow it.

This is due to the dilemma between high level challenges of project work and pressures of the deadline in the satellite project. Moreover, there is the dilemma between "student-centered learning" and "teacher-led education" in fostering qualified engineers: on the one hand students enjoy ownership of learning and motivation of group process and, on the other hand, they do require appropriate amounts of guidance.

4) Implications for Future Satellite Project
Supervision

From the data analysis, it was found that students' motivation is highly stimulated by the project management style that is built into the PBL framework, while highlighting the complexity of supervision and ambiguity of learning in groups.

Overall, the role of the supervisors, beyond creating a risk-free intellectual social environment, is to provide stu- dents with age-appropriate problems that challenge their thinking [16]. However, in the case of the satellite project, sometimes single semester groups might not have the courage to try alternative ways of thinking; in other words, the cognitive and meta-cognitive strategies needed for proceeding might not have been fully adopted and developed yet. This can have a negative impact on the motivation of the group. However, it is the authors' experience, that the common group meetings amongst all the students within the satellite project aids in creating courage and motivating such groups. Furthermore, when teachers employ methods such as "branching out, finding out, or inventing," beneficial effects for students accrue, especially in terms of their motivation, attitude towards university and self-image. All of these activities require studentstudent and student-teacher interactions [17]. As Jackson and Sinclair [18] mention, then "every learning and teaching situation is underpinned by a complex set of conditions relating to the inter-relationship between student, teacher and task" [19].

Therefore, the suggestion is that supervisors need to be more aware of the complex relationships between student, teacher and task and the students' response in order to gain the maximum impact. When the supervisors are encouraging the students to reflect on learning in practice, it is also important to make them reflect on the employed supervision practice. As regards the satellite project, the new rules to facilitate the interaction between the supervisors and the students should be built in future, especially in situations where they are faced by difficult tasks. In other words, the supervisors should pay more attention to the gap between their "invisible guidance" and students' "visible learning direction", and to facilitate the students to fill the gap in their self-management learning process. This helps to stimulate engineering students' motivation within a PBL framework.

\section{Conclusions}

During the last decade, a total of three student satellites have been developed, launched and operated exclusively by engineering students at Aalborg University in Denmark, where the PBL curriculum is implemented. Since it is a long-term and interdisciplinary project, motivating students through project management is encouraged. In this paper, focus was placed on students' perceptions of their motivation in developing the student satellite projects in a PBL environment. The aim of this study was to evaluate the efforts of project management during the satellites' development from the students' perspective, and to create a better PBL environment in the future. By interviewing 12 student participants in the satellite project of 2008-2009, valuable empirical data were obtained. Notably, the students' motivation has been highly stimulated by the project management style, where they are allowed to keep ownership of the project. A series of stimuli factors were pointed out, such as formal and informal group discussions, supervisor meetings, sharing leadership, etc. However, time schedules are a barrier to motivation, which suggests that supervisors should be more aware of the complex relationships between student, teacher, task and students' response. Accordingly, the implications for improving supervision in the satellite project have been illustrated. 


\section{REFERENCES}

[1] J. E. Holgaard, H. J. Andersen and A. Kolmos, "Cultivating creativity in engineering and science education", I van den Bogaard, M., de Graaff, E. and Saunders-Smits, G. (Eds.), Proceedings of the 37th SEFI Conference 2009: July 1-4, World Trade Centre Rotterdam - Delft University of Technology. SEFI: European Association for Engineering Education, 2009.

[2] J. D. Nielsen, X. Du and A. Kolmos, "Knowledge building approach for learning engineering: a case study of GENSO (student satellite) project", Proceedings of SEFI 2008, 36th Annual Conference, European Society for Engineering Education. Rotterdam: Sense Publishers, 2008.

[3] A. Rugarcia, R. M. Felder, D. R. Woods and J. M. Stice, "The future of engineering education I, a vision for a new century", Chem. Engr. Education, Vol. 34, No. 1, pp. 16-25, 2000.

[4] E. de Graaff and A. Kolmos, Management of Change, Implementation of Problem-Based and Project-Based Learning in Engineering. Rotterdam: Sense Publishers, 2007.

[5] J. Biggs, Teaching for Quality Learning at University. UK: Open University Press, 2007.

[6] X.Y. Du, E.de Graaff and A. Kolmos. Research on PBL Practice in Engineering Education. Rotterdam: Sense Publishers, 2009.

[7] M. Prince, "Does active learning work? A review of the research", Journal of Engineering Education, Vol. 93, No.3, 2004, pp.223231. http://dx.doi.org/10.1002/j.2168-9830.2004.tb00809.x

[8] D. R. Brodeur, P.W. Young and K. B. Blair, "Problem-Based learning in Aerospace Engineering Education", In Proceedings of the 2002 American Society for Engineering Education Annual Conference, 2002

[9] R. Norman, "Engineering a better Problem-Based Learning experience: lessons from another applied discipline," UTMJ, Vol. 88, No.3, pp.147-149, 2011.

[10] K. Schwaber, Agile Project Management with Scrum. O'Reilly Media, Inc, 2009.

[11] A. C. Edmondson and J. P. Mogelof, "Explaining psychological safety in innovation teams: organizational culture, team dynamics, or personality?" In H. S. Choi and L. L. Thompson (eds.), Creativity and Innovation in Organizational Teams. London: Lawerncec Erlbaum Associates Publishers, pp. 87-108, 2006.

[12] M. Porath and E. Jordan, "Problem-Based Learning communities: using the social environment to support creativity", In Oon-Seng
Tan (ed.), Problem-based Leaning and Creativity. Singapore: Cengage Learning Asia Pte Ltd, pp. 51-66, 2009.

[13] K. Punch. Introduction to Research Methods in Education. London: SAGE Publication Ltd, 2009.

[14] B. A .Nijstad, E. F. Rietzschel and W. Stroebe, "Four principles of group creativity". In L. Thompson and H. S. Choi (eds.), Creativity and Innovation in Organizational Teams. London: Lawrence Erlbaum Associates, pp. 161-182, 2006.

[15] E. Wenger. Communities of Practice, Learning, Meaning and Identity. New York: Cambridge University Press, 1998. http://dx.doi.org/10.1017/CBO9780511803932

[16] M. A. Runco. Creativity, Theories and Themes: Research, Development, and Practice. London: Elsvier Academic Press, 2007.

[17] A. Cropley. Creativity in Education and Learning: A Guide for Teachers and Educators. London: Kogan Page, 2003.

[18] N. Jackson and C. Sinclair, "Developing students' creativity, searching for an appropriate pedagogy", In N. Jackson, M. Oliver, M. Shaw, and J. Wisdom (eds.), Developing Creativity in Higher Education, An Imaginative Curriculum. London: Routledge, pp. 118-141, 2006.

[19] C. Zhou, A. Kolmos and J. F. D. Nielsen, "A Problem and ProjectBased Learning (PBL) approach to motivate group creativity in engineering education", International Journal of Engineering Education, Vol. 28, No. 1, pp. 3-16, 2012.

\section{AUTHORS}

J. A. Larsen is with the Department of Electronic System, Aalborg University, Denmark (e-mail: jal@es.aau.dk).

J. F. D. Nielsen is with the Department of Electronic System, Aalborg University, Denmark (e-mail: jdn@es.aau.dk).

C. Zhou is with the Department of Learning and Philosophy, Aalborg University, Denmark (e-mail: neuzcf@hotmail.com).

Submitted 21 February 2013. Published as resubmitted by the authors 26 June 2013. 